\title{
INTERVENCIÓN DEL ESTADO EN LA ECONOMÍA Y DERECHO PENAL: ESTUDIO A PROPÓSITO DE LOS CRÉDITOS CON SUBSIDIO Y LAS SUBVENCIONES*
}

Hernando A. Hernández Quintero**

Resumen: Con el abandono de los postulados del liberalismo económico clásico surge el intervencionismo del Estado en la economía, corriente que propone la concesión de créditos preferenciales y subvenciones con el fin de impulsar determinados sectores de la economía. En muchas ocasiones estos apoyos estatales son obtenidos en forma fraudulenta o son desviados hacia actividades diferentes

* El presente artículo corresponde a un avance de la investigación "Construcción de la memoria del conflicto en el sur del Tolima: hechos y actores, comprensión del conflicto armado, esclarecimiento de la verdad y aporte a la paz", que se adelanta por el Grupo Zoon Politikon de la Universidad de Ibagué, en la convocatoria interna 19-512-INT.

** Abogado de la Universidad Incca de Colombia. Magíster en Derecho Penal y Criminología de la Universidad Externado de Colombia y doctor en Derecho por la misma universidad. Especialista en Legislación Financiera de la Universidad de los Andes. Profesor de Delitos Financieros en la Especialización en Ciencias Penales y Criminológicas de la Universidad Externado de Colombia y profesor titular de la Universidad de Ibagué. Vinculado al Grupo de Investigación Zoon Politikon de la Universidad de Ibagué, ORCID 0000-0001-7366-3719. Ibagué (Colombia). Correo-e: hahernandezq@hotmail. com. Fecha de recepción: 20 de mayo de 2020. Fecha de aceptación: 12 de enero de 2021. Para citar el artículo: Hernando A. Hernández Quintero. “Intervención del Estado en la economía y Derecho Penal: estudio a propósito de los créditos con subsidio y las subvenciones”, Revista Derecho Penal y Criminología, vol. 41, n. ${ }^{\circ}$ 111, julio-diciembre de 2020, Bogotá, Universidad Externado de Colombia, pp. 133-158. DOI: https://doi.org/10.18601/01210483.v41n111.05. 
de aquellas para las que fueron otorgados, razón por la cual el legislador ha creado tipos penales para sancionar tales comportamientos. En este artículo se analiza en detalle la relación entre estos conceptos económicos y penales.

Palabras clave: intervención del Estado en la economía; derecho penal; crédito; subvención.

\title{
INTERVENTION OF THE STATE IN THE ECONOMY AND CRIMINAL LAW: STUDY ON CREDITS WITH BENEFIT AN THE GRANTS
}

\begin{abstract}
With the abandonment of the postulates of classical economic liberalism, state interventionism in the economy arises, a current that proposes the granting of preferential credits and subsidies in order to promote certain sectors of the economy. On many occasions these state supports are obtained fraudulently or are diverted to different activities for which they were granted, which is why the legislator has created criminal types to sanction these behaviors. This article analyzes in detail the relationship between these economic and criminal concepts.
\end{abstract}

Keywords: State intervention in the economy; criminal law; credit; subsidy.

\section{CONCEPTOS GENERALES DE LA INTERVENCIÓN DEL ESTADO EN LA ECONOMÍA}

Como lo advierte la doctrina, en el Estado liberal, que tuvo vigencia entre el siglo XVII y principios del XIX, se limitaba la injerencia de lo público en lo privado, que en la economía se traduce en no interferir en la iniciativa privada y la gestión de los negocios, limitando la acción del Estado a la garantía de las libertades individuales, la protección de la paz ciudadana y la defensa de las fronteras ${ }^{1}$. En esta corriente clásica del liberalismo, conocida como "concepción demoliberal”, "economía de mercado" o "economía del lado de la oferta", se impone la tesis de Adam Smith, según la cual el mercado se autorregula, se autocontrola, pues existe una especie de mano invisible que lo reacomoda cuando presenta fallas ${ }^{2}$.

A finales del siglo XIX y principios del XX, con el abandono del Estado liberal por parte de las sociedades posindustriales, aparece el Estado intervencionista y, con él, el

1 David Guinard Hernández. "La 'regulación económica' como instrumento de dirección estatal en la economía”, Revista digital de Derecho Administrativo, n. ${ }^{\circ} 18$, julio-diciembre, Bogotá, Universidad Externado de Colombia, 2017,p. 178.

2 Adam Smith. La riqueza de las naciones, Madrid, Alianza, 2008, p. 554. 
Estado social de derecho. En él, respetando la propiedad privada, la empresa individual y la iniciativa privada, la dirección general de la economía está a cargo del Estado y estos derechos se pueden limitar en procura del bien común. Esta corriente, conocida también como "economía mixta", "economía social", "regulada" o "intervencionista", se manifiesta claramente en las constituciones de México, de 1917; Weimar de 1919, en Alemania; España, de 1931, y en Colombia, en la reforma constitucional de 1936.

Por intervención del Estado en la economía se ha entendido el conjunto de normas con las cuales se pretende regular y delimitar la autonomía de los particulares con el fin de garantizar el logro de los intereses de la comunidad, esto es, del bien común. O, como lo enseña el constitucionalista Jacobo Pérez Escobar, "la intervención económica es aquella que tiene por objeto racionalizar y planificar la economía con el fin de lograr el desarrollo económico y el progreso social"33.

Sobre la materia, el Consejo de Estado ha concluido:

La intervención del Estado en la economía es una injerencia del poder público en una cualquiera de las fases del proceso económico, con el fin de producir consecuencias o efectos, también de tipo económico y que se traduce en limitaciones de la actividad privada o de la libre empresa.

[...]

Por ello la intervención desborda el simple control de la pura legalidad y se expresa en actos que persigan un resultado económico concreto: aumento en la producción, incremento cualificado de la misma, redistribución del ingreso, aumento del poder adquisitivo del consumidor sobre la demanda, etc. ${ }^{4}$.

Esta intervención del Estado en la economía puede efectuarse de múltiples formas, como ha sucedido en Colombia. Bien puede tratarse de estímulos a la iniciativa privada, como la creación del Certificado de Reembolso Tributario (CERT) para los exportadores; para fomento a través del crédito, como los préstamos subsidiados de la Ley 5 de 1973 para los agricultores y los préstamos a través del Fondo para el Financiamiento del Sector Agropecuario (Finagro); o bien de la organización y dirección de la producción hacia un sector determinado. La intervención comentada, también puede llevarse a cabo por conducto del control de precios, de tarifas o de calidades, gestión a cargo de la Superintendencia de Industria y Comercio. Es corriente, además, ya en un plano más sustancial, la coparticipación del Estado con la iniciativa privada, al concurrir en las empresas de economía mixta; la creación de empresas puramente estatales que compiten con las particulares y aun, en ocasiones,

3 Jacobo Pérez Escobar. Derecho constitucional colombiano, Bogotá, Horizontes, 1974, p. 244.

4 Consejo de Estado, Sala de lo Contencioso Administrativo, Sección Primera, febrero 4 de 1976, consejero ponente: Carlos Galindo Pinilla. 
se excluye la competencia privada, como en los Ferrocarriles Nacionales, las comunicaciones telefónicas o telegráficas, el acueducto, la energía; o el sector bancario, en el que se encuentran entidades privadas, oficiales y mixtas. Por otra parte, el Estado puede intervenir drásticamente entidades a las que se les había concedido la explotación de un determinado renglón de la economía, como sucedió en 1982 con la nacionalización de algunos bancos como el del Estado y el Grupo Grancolombiano, o la liquidación del Banco Nacional y durante la crisis de finales de los años noventa (1998-2001) cuando se intervinieron con fines de liquidación 24 establecimientos de crédito $^{5}$.

Recogiendo los criterios expresados, la Corte Constitucional, en la sentencia C-150 del 25 de febrero de 2003, precisó que la intervención del Estado en la economía puede ser global, sectorial o particular; directa o indirecta; unilateral o convencional, y por vía directa o por vía de gestión. Estos criterios se reiteran en las sentencias C-042 del 1. ${ }^{\circ}$ de febrero de 2006 y C-186 del 16 de marzo de 2011.

\subsection{La intervención del Estado en la economía en la Constitución colombiana}

En la economía colombiana y, por ende, en la actividad financiera, hay un claro intervencionismo de Estado. La intervención es compartida por el legislativo y el ejecutivo por mandato de la Constitución Política de 1991 (art. 150, nums. 8, 13, 19, 21 y 22 ; art. 189 , num. 24 y 25; art. 333; art. 334; art. 335; art. 371, art. 372 y art. 373). Como lo señala Hugo Palacios Mejía, a partir de la reforma de 1968 la Constitución se introdujo en el artículo 32, hoy 334, el principio de que la "dirección general de la economía estará a cargo del Estado" y ello significa que el "dirigismo" económico ha sido elevado a "canon constitucional" 6 . Se ha dicho, con razón, que esta norma es un límite general a la garantía, general también, que contiene la Constitución respecto a la libertad de empresa y de la iniciativa privada.

En la Constitución de 1886 encontramos el primer antecedente de la intervención del Estado en la economía colombiana. A pesar de que los constituyentes se opusieron a llevar a la Carta los temas económicos porque estimaban que no eran suficientemente importantes para aparecer allí, se advierte que el interés privado debe ceder al interés público y se consagran disposiciones relativas a la propiedad (art. 32). Otras normas otorgaron a las autoridades la facultad de inspeccionar las industrias, las profesiones, las instituciones de utilidad común, la educación, los bancos de emisión y demás establecimientos de crédito (art. 44, inciso 2; art. 120, num. 17).

5 AA. VV. Crisis financiera colombiana en los años noventa, origen, resolución y lecciones institucionales, Bogotá, Universidad Externado de Colombia, 2009, p. 105.

6 Hugo Palacios Mejía. La economía en el derecho constitucional colombiano, t. I, Bogotá, Biblioteca ANIF de Economía, 1975, p. 220. 
En el artículo 76, numeral 15, aparece la facultad atribuida al Congreso para "fijar la ley, tipo y denominación de la moneda, y arreglar el sistema de pesas y medidas".

De la reforma constitucional de 1910 se destaca la prohibición de efectuar cualquier nueva emisión de papel moneda de curso forzoso y el establecer los monopolios estatales como arbitrio rentístico (art. 7) ${ }^{7}$. Luego, en la reforma de 1936, imbuida de los vientos reformadores de la Revolución en Marcha, aparece el primer mandato específico en cuanto a la intervención estatal, fórmula sugerida por el entonces ministro de Gobierno Darío Echandía, con el argumento de la necesidad de poner los preceptos constitucionales a tono con las concepciones modernas del Estado, en lo relacionado con la regulación de la economía y la protección al trabajo.

Así, en el artículo 11 de esta importante reforma constitucional se consagró lo siguiente:

El Estado puede intervenir, por medio de leyes, en la explotación de industrias o empresas públicas y privadas con el fin de racionalizar la producción, distribución y consumo de las riquezas, o de dar al trabajador la justa protección a que tiene derecho.

Parágrafo: Las leyes que se dictan en ejercicio de la facultad que otorga este artículo, requieren para su aprobación el voto favorable de la mayoría absoluta de los miembros de una y otra cámara [énfasis agregado].

El artículo 4. ${ }^{\circ}$ del Acto Legislativo 1 de 1945 modificó en los siguientes términos el texto comentado en precedencia:

El Estado puede intervenir por mandato de la ley en la explotación de industrias o empresas públicas o privadas, con el fin de racionalizar la producción, distribución y consumo de las riquezas, o de dar al trabajador la justa protección a que tiene derecho.

Esta función no podrá ejercerse en uso de las facultades del artículo 76, ordinal 12, de la Constitución [énfasis agregado].

De esta forma, desaparece la exigencia de la mayoría especial y la expresión "por medio de leyes", se cambió por la de "por mandato de la ley".

En 1966, el Gobierno presentó al parlamento una propuesta de reforma al artículo 32 de la Carta, que consistía, fundamentalmente, en la supresión del inciso segundo de la disposición, con el propósito de permitir la intervención en la economía cuando

7 Ciro Angarita Barón. "La libertad económica en la jurisprudencia de la Corte Constitucional: aproximación fugaz”, en AA. VV. Constitución económica colombiana, Bogotá, El Navegante, 1997, p. 169. 
el Gobierno fuere revestido por el Congreso de facultades extraordinarias, precisas y pro tempore. Después de conocidos acuerdos políticos entre los parlamentarios del partido de gobierno y el Movimiento Revolucionario Liberal (MRL), liderado por el senador Alfonso López Michelsen, se aprobó, en la reforma de 1968, la siguiente redacción del artículo 32 de la Constitución:

Artículo 32. Se garantizan la libertad de empresa y la iniciativa privada dentro de los límites del bien común, pero la dirección general de la economía estará a cargo del Estado. Este intervendrá, por mandato de la ley, en la producción, distribución, utilización y consumo de los bienes y en los servicios públicos y privados, para racionalizar y planificar la economía a fin de lograr el desarrollo integral. Intervendrá también el Estado, por mandato de la ley, para dar pleno empleo a los recursos humanos y naturales, dentro de una política de ingresos y salarios, conforme a la cual el desarrollo económico tenga como objetivo principal la justicia social y el mejoramiento armónico e integrado de la comunidad, y de las clases proletarias en particular.

Por otra parte, el artículo 120, numeral 14, de la reforma de 1968 instituyó también la intervención presidencial en el ahorro privado y en el banco de emisión (Banco de la República), al preceptuar:

Corresponde al presidente de la República, como jefe del Estado y suprema autoridad administrativa: ejercer, como atribución constitucional propia, la intervención necesaria en el banco de emisión y en las actividades de personas naturales o jurídicas que tengan por objeto el manejo o aprovechamiento y la inversión de los fondos provenientes del ahorro privado.

A su vez, el numeral 15 de la disposición comentada anunciaba como facultad del primer mandatario "Ejercer la inspección necesaria sobre los demás establecimientos de crédito y las sociedades mercantiles, conforme a las leyes".

Se observa así, como lo advierte Hugo Palacios Mejía, que la reforma constitucional de 1968 representa, en el siglo Xx, el momento significativo

[...] de una tendencia a trasladar al presidente, y en general a la rama ejecutiva del poder público, funciones reguladoras que antes estaban atribuidas al Congreso. Ejemplos de esa tendencia son la restricción de la iniciativa legislativa de los congresistas en ciertos asuntos (que ya se había iniciado en la reforma del 45); y la regla según la cual el Congreso no podría tratar temas sino por medio de "leyes marco".

8 Hugo Palacios Mejía. "Notas acerca de la facultad de regular la economía en la Constitución de 1991", en Derecho Público, n. ${ }^{\circ}$ 1, Bogotá, Universidad de los Andes, 1992, p. 41. 
De las consideraciones precedentes se colige que en Colombia se pretendió, hasta la reforma de 1991, que la intervención del Estado en la economía (producción, distribución y consumo de los bienes y servicios) se realizara con normas dictadas por el Congreso, pero también por el ejecutivo, a fin de adoptar medidas que no permitirían trasegar el camino parlamentario, esto es, para atender situaciones de emergencia.

\subsection{La intervención del Estado en la economía en la Constitución Política de 1991}

En la reforma a la Carta efectuada por el constituyente en 1991 se consagraron con generosidad los derechos y garantías de naturaleza económica, de tal forma que llevó a los tratadistas del derecho constitucional a afirmar que los temas económicos tienen tanta presencia cuantitativa y cualitativa en la nueva Constitución que bien puede decirse que junto a la Constitución Política se perfila una constitución económica. Así, en el capítulo I del título II se reitera: el derecho al trabajo (art. 25), el derecho a escoger libremente profesión y oficio (art. 26), la prohibición de la confiscación (art. 34) y el derecho de asociación y de formar sindicatos (art. 38 y 39). Se crea también el derecho a la libre circulación (art. 24).

En el capítulo II del mismo título (De los derechos sociales, económicos y culturales) se insiste en la protección al trabajo (art. 53), se garantiza la negociación colectiva (art. 55) y el derecho a la huelga (art. 56), se faculta al legislador para dar a los trabajadores participación en la gestión de las empresas (art. 57), se garantiza, dentro de ciertos límites, la propiedad privada (art. 58), se establece la responsabilidad de las autoridades para las expropiaciones (art. 59), se ordena al Estado promover el acceso a la propiedad (arts. 60 y 84), se protege la propiedad intelectual (art. 61), se garantiza las donaciones (art. 62), se permite al legislador dar carácter de inalienables, imprescriptibles e inembargables a ciertos bienes (art. 63), se ordena proteger la producción de alimentos (art. 65) y tener en cuenta los ciclos de las cosechas y los precios al regular el crédito agrícola (art. 66), se reglamenta el espectro electromagnético (art. 75) y se precisa cómo debe regularse la televisión e intervenir en ella (arts. 76 y 77).

En el capítulo III de ese mismo título II (Derechos colectivos y del ambiente) se faculta al legislador para regular el control de calidad de bienes y servicios (art. 80) y se prohíbe la fabricación, importación, posesión y uso de armas nucleares (art. 81).

Por otra parte, el intervencionismo del Estado en la economía se concretó en el título XII (Del régimen económico y de la hacienda pública), particularmente en los artículos 333, 334 y 335. 
De las normas citadas, se puede afirmar que si bien en el artículo 333 se consagra una serie de principios de libertad económica ${ }^{9}$, ella está inmediatamente limitada por el "bien común", concepto tildado de difuso por el profesor Hernán Toro Agudelo, al debatirse la reforma de 1968. Sin embargo, la Corte Constitucional ha venido desarrollando este criterio en decisiones como la contenida en la sentencia T-251 del 30 de junio de 1993. Además, como acertadamente lo sostiene Luis Carlos Sáchica al comentar esta disposición constitucional (art. 333),

Allí también se afirma que la libre competencia supone responsabilidades. Misteriosa expresión que no queda regida por ningún criterio. Desde luego, será la ley la que establezca y mida caprichosamente, porque la Constitución dejó suelta esta declaración limitativa. Porque ¿responsabilidades de qué clase, con quiénes, en qué medida y consecuencias? ${ }^{10}$

Empero, la libre competencia económica fue explicada ampliamente en la Asamblea Nacional Constituyente de 1991 por Guillermo Perry Rubio, con los siguientes argumentos:

Cuando la competencia económica no es libre o es desleal o injusta se produce un daño que afecta no sólo a determinados productores de bienes y servicios o a los consumidores respectivos, sino también al conjunto de la colectividad. Por el contrario, cuando la competencia no adolece de estas fallas, es decir, cuando es libre, leal y justa, el mercado, mediante la acción de las fuerzas de la oferta y la demanda, se torna eficiente y provee grandes beneficios a la comunidad ${ }^{11}$.

Por esta vía, concluye el autor que el derecho a la libre competencia beneficia tanto a los productores como a los consumidores y usuarios, toda vez que se limita el poder monopólico o el abuso de la posición dominante ${ }^{12}$.

La Corte Constitucional en decisión T-425 del 24 de junio de 1992 ha concluido que la libertad económica a que se refiere la carta fundamental " [...] es una facultad que tiene toda persona de realizar actividades de carácter económico, según sus preferencia o habilidades, con miras a crear, mantener o incrementar su patrimonio" 13 . Además, la alta corporación declara en esta sentencia que dicha libertad económica tiene rango de derecho fundamental, puesto que la Constitución de 1991 amplió

9 El concepto de libertad económica ha sido analizado por la Corte Constitucional en varias decisiones, entre las cuales destacamos la T-419 del 17 de junio de 1992.

10 Luis Carlos Sáchica. Nuevo constitucionalismo colombiano, 10. a ed., Bogotá, Temis, 1992, p. 328.

11 Guillermo Perry Rubio. "Estado y sector privado en la Constitución de 1991", en Constitución Económica Colombiana, Bogotá, El Navegante, p. 128.

12 Ibídem, p. 128.

13 Cfr. Corte Constitucional. Sentencia T-425 del 24 de junio de 1992. 
significativamente su ámbito y grado de protección ${ }^{14}$. Asimismo sostiene que el artículo 333 reconoce dos tipos de libertades: la de empresa y la de competencia.

Ahora bien. El propio artículo 333, en su inciso $5^{\circ}$, precisa como límites de la libertad económica: el interés social, el ambiente y el patrimonio cultural ${ }^{15}$, los cuales deben ser establecidos por la Ley; es decir, transfiere al legislativo la tarea de señalar dichos parámetros. Por ello, en la sentencia C-792 de 2002 la Corte Constitucional señala, con razón, que "la libertad económica no es un derecho absoluto pues es el mismo constituyente el que permite que el legislados le imponga límites para realizar fines constitucionalmente valiosos [...]".

En torno al artículo 334, que encuentra claro antecedente en el 32 de la anterior Constitución, se observa que la política del Estado trazará el rumbo a la actividad económica privada, en razón del "dirigismo económico" que allí se establece. Es preciso, además, armonizar sus mandatos con la clara prescripción del numeral 21 del artículo 150, que obliga al Congreso a precisar sus fines y alcances y los límites a la libertad económica cuando expida las leyes de intervención económica a que se refiere el artículo 334 .

De esta manera, se concluye que la intervención del Estado en la Constitución Política de 1991 es compartida entre el legislativo y el ejecutivo, como lo dejó sentado la Corte Constitucional en la sentencia C-042 del $1 .^{\circ}$ de febrero de 2006, con ponencia de la magistrada Clara Inés Vargas, al expresar:

El diseño establecido por el constituyente para que el Estado interfiera en circuito económico implica la actuación del legislador y de la administración. Es por ello que el artículo 150-21 superior faculta al Congreso de la República para elaborar las normas de intervención económica, mientras el 334 habilita a la administración para intervenir por mandato de la ley, entre otras actividades, en la distribución, utilización y consumo de bienes, entre ellos los combustibles, para racionalizar la economía con el fin de conseguir el mejoramiento de la calidad de vida de los habitantes del territorio nacional ${ }^{16}$.

Es claro también que, por mandato constitucional, se adoptó en Colombia el modelo de economía social de mercado, pero con una marcada intervención estatal. Así lo precisó la Corte Constitucional en las sentencias C-228 del 24 de marzo de 2010 y C-197 del 14 de marzo de 2012. En esta última se afirma:

14 Sobre el tema puede consultarse también la sentencia C-616 de 2001 de la Corte Constitucional.

15 Cfr. Corte Constitucional. Sentencia C-197 del 14 de marzo de 2012. Este criterio se sostiene también en las sentencias: C-616 de 2001, C-389 de 2002, C-992 de 2006, C-489 de 2005 y C-228 de 2010.

16 Este criterio se reitera en la sentencia C-197 del 14 de marzo de 2012. 
La Constitución de 1991, especialmente al adoptar un modelo de Estado Social de Derecho, introdujo un modelo de economía social de mercado en el que, de un lado, se admite que la empresa es motor del desarrollo social (artículo 333 superior), y por esta vía, se reconoce la importancia de una economía de mercado y de la promoción de la actividad empresarial, pero por otro, se asigna al Estado no solo la facultad sino la obligación de intervenir en la economía con el fin de remediar las fallas del mercado y promover el desarrollo económico y social (artículos 333, 334 y 335 constitucionales) [énfasis nuestro].

La intervención del Estado en la economía busca entonces conciliar los intereses privados presentes en la actividad empresarial con el interés general involucrado en el buen funcionamiento de los mercados para lograr la satisfacción de las necesidades de toda la población en condiciones de equidad. En este sentido, el artículo 334 de la Carta dispone que el Estado intervendrá en la economía para racionalizarla "con el fin de conseguir el mejoramiento de la calidad de vida de los habitantes, la distribución equitativa de las oportunidades y los beneficios del desarrollo y la preservación de un ambiente sano" ${ }^{17}$.

Ahora bien: a través del Estado de excepción consagrado en el artículo 215 de la Constitución, conocido como “emergencia económica social y ecológica”, el Gobierno puede intervenir en la economía, dictando decretos con fuerza de ley para conjurar situaciones que amenacen el orden económico social y que no permitan esperar al lento tránsito de la actividad parlamentaria. Tales disposiciones se dirigen, en forma prioritaria, a autorizar la concesión de créditos flexibles o a entregar subsidios y auxilios que rescaten a las empresas o alivien la situación de los particulares, como sucedió en la emergencia declarada por el Gobierno mediante el Decreto 417 del 17 de marzo de 2020. Incluso, estas normas pueden ser de carácter penal, como se evidencia en los estados de excepción decretados en 1982, 2010 y 2020. Tal posibilidad, según lo expresado por la Corte Constitucional en la sentencia C-224 de 2009, se ajusta a la Carta Política, con la aclaración de que la vigencia de los decretos dictados bajo el amparo de la emergencia económica no puede exceder de un año ${ }^{18}$.

\section{LOS CRÉDITOS SUBSIDIADOS Y LAS SUBVENCIONES COMO POLÍTICA DE INTERVENCIÓN DEL ESTADO EN LA ECONOMÍA}

Sin discusión alguna, los créditos subsidiados y las subvenciones constituyen elementos centrales de la intervención del Estado en la economía. A través de ellos

17 Sobre la intervención del Estado en la economía también puede consultarse las sentencias: C-398 del 7 de septiembre de 1995; C-150 del 25 de febrero de 2003; C-865 del 7 de septiembre de 2004; C-228 del 24 de marzo de 2010 y C-263 del 6 de abril de 2011.

18 La posición mayoritaria no fue compartida por el magistrado Humberto Sierra Porto, quien aclaró su voto, señalando que la competencia de crear tipos penales es exclusiva del Congreso de la República. 
se procura el estímulo necesario para que los ciudadanos encausen sus actividades privadas al desarrollo de algunos sectores económicos en los que el Estado tiene interés. Por ejemplo, la industria, la agricultura, la ganadería, la explotación de hidrocarburos, las exportaciones, entre otros. En momentos de crisis, estos beneficios son indispensables para superar la desaceleración económica e incluso la recesión.

Comoquiera que no puede darse el mismo alcance al concepto de subvención, aunque algunos tratadistas los unifican, efectuamos a continuación un breve análisis de ellos.

\subsection{El crédito dirigido y subsidiado}

Tradicionalmente se ha entendido por crédito la operación mediante la cual una entidad financiera abre un cupo a una persona para que pueda usar determinados recursos, con la obligación de devolverlos, bien en su totalidad o por cuotas, que por lo general se incrementan con el interés compensatorio y remuneratorio que debe reconocer el prestatario al prestamista. Empero, como ya se señaló, en ciertas ocasiones el Estado se propone desarrollar algún sector específico de la economía y, a través de bancos de segundo piso, destina ingentes recursos que luego se trasladan a los ciudadanos por conducto de entidades financieras, usualmente con tasas de interés privilegiadas y con generoso tiempo para su cancelación. Esta figura se ha denominado "crédito dirigido y subsidiado".

En Colombia, la literatura enseña que los primeros intentos para promover la actividad económica utilizando el crédito subsidiado se dieron en 1924, con la creación del Banco Agrícola Hipotecario para la adquisición de tierras o fomentar las actividades de cooperativas agrícolas. Más tarde, en 1940, se intensifican con el nacimiento del Instituto de Fomento Industrial (IFI) ${ }^{19}$ y luego tienen un gran impulso con las facultades que otorgadas al Banco de la República mediante la reforma de sus funciones en 1951 y aún subsisten, a pesar de la liberación financiera que se vivió en la década de los noventa.

En efecto, la Misión del Banco Internacional de Reconstrucción y Fomento, que visitó el país en 1949, recomendó reconsiderar las estrictas disposiciones que regían para los bancos comerciales y sugirió “que el volumen del crédito fuera controlado por el Banco de la República, con el objeto de expandirlo o restringirlo, según lo demandara la situación económica" ${ }^{20}$. El Gobierno nacional, en atención a tal sugerencia, consideró prudente encausar el crédito hacia las actividades productivas,

19 José Antonio Ocampo, Paola Arias y Juan David Torres. "La banca nacional de desarrollo en Colombia”, en Ensayos de Política Económica, n. ${ }^{\circ}$ 88, Bogotá, Banco de la República, 2018, p. 4.

20 Jorge Enrique Ibáñez Najar. "La reforma de 1951", en El Banco de la República: antecedentes, evolución y estructura, Bogotá, Banco de la República, 1990, p. 444. 
estableciendo estímulos especiales para los préstamos destinados a tal fin ${ }^{21}$. Este propósito se concretó por medio del Decreto 384 de 1950 y el 1249 del mismo año, que lo reglamentó. Estas normas se han considerado el origen del crédito de fomento en la modalidad de redescuento, cuyo atractivo estaba en el margen diferencial entre las tasas de colocación y las de redescuento ${ }^{22}$.

En 1963, con la Ley 21, se creó la Junta Monetaria, entidad a la que se encargó establecer la política monetaria, cambiaria y crediticia que debía ejecutar el Banco de la República. En ejercicio de la tarea crediticia, la Junta dio vida al Fondo Financiero Agrario (FFA ${ }^{23}$, que luego se transformó en el Fondo Financiero Agropecuario, el Fondo Financiero Industrial (FFI) ${ }^{24}$ y el Fondo de Promoción de Exportaciones (Proexpo) ${ }^{25}$, que fueron administrados por el Banco de la República hasta 1990, cuando, previendo la reforma a esta entidad que se plasmó en la Constitución de 1991, se convirtieron en la Financiera de Desarrollo Territorial S. A. (Findeter) ${ }^{26}$, el Fondo para el financiamiento del sector agropecuario (Finagro) ${ }^{27}$ y el Banco de Desarrollo empresarial $(\text { Bancoldex })^{28}$. Los fondos y las entidades que los sustituyeron se han encargado de promover los créditos de redescuento dirigidos a sectores priorizados en la agenda pública, tales como la agricultura, las pequeñas y medianas empresas manufactureras, las exportaciones no tradicionales, la infraestructura local y la electricidad ${ }^{29}$.

En 1973 de dictó la Ley 5, con el propósito de estimular la capitalización del sector agropecuario. Los créditos con tasa subsidiada que se concedieron al amparo de la mencionada norma lograron un amplio desarrollo del sector agropecuario e industrial en el país y muchos ciudadanos incrementaron en forma considerable sus capitales de trabajo. Empero, como consecuencia del elevado subsidio de las tasas de interés, en varias ocasiones fue necesario acudir al crédito del Banco de la República, lo cual tuvo un gran impacto negativo en la balanza de pagos y en la evolución de los precios en el país ${ }^{30}$. Tal situación condujo a que esas tasas de interés se fueran ajustando

21 Jorge Enrique Ibáñez Najar. "La reforma de 1951”, cit., p. 445.

22 Hernando J. Gómez. “Antecedentes y evolución del crédito de fomento en Colombia y su relación con el Banco Central”, en El banco de la República, antecedentes, evolución y estructura, Bogotá, Banco de la República, 1990, p. 685.

23 El FFA se creó por medio de la Resolución 23 de 1966 de la Junta Monetaria.

24 El Fondo Financiero Industrial fue creado por la Resolución 54 de 1968.

25 Proexpo fue creado por el Decreto-Ley 444 de 1967, conocido como el Estatuto Cambiario.

26 Findeter fue creada por medio de la Ley 57 de 1989.

27 Finagro fue creado por medio de la Ley 16 de 1990.

28 Bancoldex fue creado por medio de la Ley 7 de 1991.

29 José Antonio Ocampo, Paola Arias, y Juan David Torres. "La banca nacional de desarrollo en Colombia", cit., p. 10.

30 Hernando J. Gómez. “Antecedentes y evolución del crédito de fomento en Colombia y su relación con el Banco Central”, cit., p. 689. 
gradualmente para buscar un mayor equilibrio financiero (captación, colocación), es decir, en condiciones de mercado ${ }^{31}$, aspecto que ha influido para que en nuestros días muchos agricultores - por ejemplo, los arroceros- miren con poco entusiasmo estos créditos y utilicen con mayor frecuencia los préstamos de los grandes molineros que, muchas veces, precompran las cosechas a través de estos préstamos ${ }^{32}$.

Ahora bien: cuando se contó con tasas de interés subsidiadas, se presentó una demanda desproporcionada de crédito ${ }^{33}$ y así como muchos beneficiarios lo utilizaron adecuadamente, otros ciudadanos los desviaron hacia actividades que estimaron más rentables y de menor riesgo, situación que llevó a que el legislador creara mecanismos de control a la inversión y un sistema de sanciones ${ }^{34}$. De esta forma, se incluyó en el Código Penal de 1980 una conducta punible conocida como "aplicación fraudulenta de crédito oficialmente regulado”, que analizaremos más adelante.

\subsection{Subvenciones}

Como ya se indicó en el presente escrito, para incentivar algunos renglones de la actividad productiva en los que los países tienen especial interés, los Estados, en desarrollo de la intervención positiva en la economía, otorgan subvenciones a los particulares.

Por subvención se entiende, según el criterio de María del Carmen Gómez Rivero, una contribución patrimonial, en dinero o en especie, que beneficie económicamente al adjudicatario sin que tenga carácter devolutivo, y que haya sido concedida por la Administración Pública ${ }^{35}$. Otros autores incluyen el criterio de que estas subvenciones son atribuciones patrimoniales a fondo perdido ${ }^{36}$.

Ahora bien: si se tiene claro que la subvención es a fondo perdido y que no se tiene la obligación de devolverla al Estado, es necesario precisar que debe representar una contrapartida para el Estado; por ejemplo, la mejora de la producción o la generación de empleos o divisas, entre otros. Así lo dejó sentado la Corte Constitucional en la sentencia C-324 del 13 de mayo de 2009, al estudiar las diferencias jurídicas entre

31 Francisco J. Ortega. "Evolución y políticas de administración de las líneas de crédito externo para el sector privado", en Tres banqueros centrales, Adolfo Meisel Roca y María Teresa Ramírez (eds.), Bogotá, Banco de la República, 2017,p. 142.

32 Sobre el tema pueden consultarse las entrevistas realizadas en nuestra investigación con arroceros del departamento del Tolima.

33 Joaquín de Pombo. "Dinámica del sector agrícola colombiano", en AA. vV. La economía colombiana, temas de comercio y desarrollo, Bogotá, Banco de la República, 1995, p. 259.

34 Ibídem, p. 259.

35 María del Carmen Gómez Rivero. "Fraude a subvenciones", en AA. vv. Diccionario de derecho penal económico, Javier Boix Reig (dir.) y Paz Lloria García (coord.), Madrid, Iustel, 2008, p. 499.

36 Germán Fernández Farreres. La subvención, concepto y régimen jurídico, Madrid, Instituto de Estudios Fiscales, 1983, p. 584. 
este mecanismo y los auxilios parlamentarios. En el proveído se concretó que las subvenciones y los auxilios que otorga el Estado pueden:

[... [2] Derivarse de la facultad de intervención del Estado en la economía y, en consecuencia, orientarse al estímulo de una determinada actividad económica; asignación que por mandato expreso del artículo 334 superior debe comportar una contraprestación, es decir, debe implicar un retorno para la sociedad en su conjunto, sin el cual la subvención carece de equidad y de toda justificación.

El profesor Jason Alexander Andrade Castro, en la misma línea del tratadista español Luis Arroyo Zapatero, señala que existen un criterio amplio y otro restringido en relación con la subvención. El primero se relaciona con la atribución patrimonial llevada a cabo por el Estado por vía del gasto público o por vía de menores ingresos públicos, tales como las exenciones y las desgravaciones. El segundo abarca las prestaciones dirigidas específicamente a los particulares y, de manera exclusiva, a los agentes económicos ${ }^{37}$.

Los elementos de la subvención han sido resumidos con claridad por la doctora Virginia Sánchez López, quien los identifica como subjetivos y objetivos. De los primeros forman parte el sujeto otorgante, que debe ser el sector público, y el sujeto beneficiario, que resulta ser un particular, bien como persona natural o jurídica. En cuanto a los objetivos, los integran: la atribución patrimonial, el carácter no devolutivo y la finalidad a la que la subvención se dirige ${ }^{38}$.

En Colombia la concesión de subvenciones ha sido recurrente a lo largo de la historia. Así, encontramos el Plan Vallejo, que se proyectó en 1959 y empezó a desarrollarse en 1961 y, finalmente, se incluyó en el Decreto Ley 444 de 1967, conocido como el Estatuto Cambiario. Este proyecto, de gran trascendencia en la vida económica de nuestra nación, permitía la importación de materias primas, insumos y bienes de capital libres de derechos aduaneros a cambio de realizar exportaciones equivalentes a dichas importaciones.

En el mismo Estatuto Cambiario se creó el incentivo del Certificado de Abono Tributario (CAT), título de deuda pública interna que se concede en favor de quienes acrediten haber efectuado en forma legal exportaciones de bienes diferentes al café, el petróleo y sus derivados, y los cueros crudos de res. El beneficio consiste en la devolución de los impuestos indirectos pagados para la producción y exportación del producto exportado. Con la Ley 48 de 1983, este título se convirtió en el Certificado de Rembolso

37 Jason Alexander Andrade Castro. "Aproximación a los nuevos tipos penales para combatir la corrupción”, en XXXIV Jornadas Internacionales de Derecho Penal. Retos del derecho penal contemporáneo: corrupción y seguridad ciudadana, Bogotá, Universidad Externado de Colombia, 2012, pp. 39-40.

38 Virginia Sánchez López. El delito de fraude a subvenciones en el nuevo Código Penal, Madrid, Constitución y Leyes, pp. 101-108. 
Tributario (CERT), que permite anualmente grandes incentivos a los exportadores, según el porcentaje que por cada período establece el Gobierno nacional ${ }^{39}$. Recientemente, con la expedición de la Ley 1819 de 2016, conocida como de la reforma tributaria estructural, se extendió el CERT a las inversiones de exploración y explotación de hidrocarburos y exploración en minería ${ }^{40}$, con lo que se busca compensar las pérdidas por la baja considerable que ha tenido el precio del petróleo en los últimos años.

Con el propósito de estimular a las personas naturales o jurídicas que ejecuten proyectos de inversión financiados, total o parcialmente, con crédito redescontado a Finagro, la Ley 101 de 1993 creó el Incentivo a la Capitalización (ICR). Por medio de la Ley 139 de 1994 se creó el Certificado de Incentivo Forestal, cuyo fin es promover la realización de inversiones directas en nuevas plantaciones forestales de carácter protector-productor, en terrenos de aptitud forestal.

Por otra parte, con el propósito de proteger los ingresos de los productores colombianos en razón de la internacionalización de la economía y, en especial, por el tratado de libre comercio suscrito por nuestro país con los Estados Unidos el 22 de noviembre de 2006, el Congreso, a instancias del Gobierno, expidió la Ley 1143 de 2007, conocida como "Agro Ingreso Seguro" (AIS):

[...] concebido como una política pública de ejecución sucesiva con dos grandes componentes: uno, de ayudas directas destinadas a apoyar, durante un período fijo, a sectores considerados sensibles, para reforzar su competitividad; otro, de incentivos a la productividad, sin límite en el tiempo, orientado a estimular ese mismo aspecto en todos los sectores ${ }^{41}$.

Ante la necesidad de mitigar la crisis del sector cafetero, ocasionada por la baja del precio internacional del grano que afectaba la sostenibilidad y estabilidad del sector, el Comité Nacional de Cafeteros de Colombia, el 17 de octubre de 2012, aprobó la creación del programa denominado “Apoyo al Ingreso del Caficultor”, el cual se fortaleció con recursos del presupuesto nacional. Luego, el Comité de Cafeteros, por medio de la Resolución 5 de 2013, ajustó el programa y se cambió su nombre por el de Programa de Protección del Ingreso Cafetero (PIC). Cabe destacar que la Federación Nacional de Cafeteros ha venido entregando estos subsidios en su condición de

39 Estos subsidios no son nuevos en nuestro país, pues en el siglo XIX se abonaba a los exportadores de algodón un monto sobre el valor exportado. Muriel Laurent. Contrabando en Colombia en el siglo XIX: prácticas y discursos de resistencia y reproducción, Bogotá, Universidad de los Andes, 2008 , p. 81 .

40 El Decreto 2253 del 29 de diciembre de 2017 reglamentó el artículo 365 de la Ley 1819 de 2016 , que creó el CERT para incentivar la inversión en la exploración y explotación de hidrocarburos y exploración de minería.

41 Corte Suprema de Justicia, sentencia SP 9225-14, rad. 37562. 
administradora del Fondo Nacional del Café, una cuenta parafiscal cuyos recursos son de naturaleza pública.

El Gobierno del presidente Iván Duque, con el fin de apoyar a las empresas ante la grave crisis económica que afronta Colombia como consecuencia de la pandemia conocida como la covid-19, al amparo de la emergencia económica declarada por el Decreto 637 de 2020, creó el Programa de Apoyo al Empleo Formal (PAEF), por medio del cual se estableció el subsidio de la nómina por el término de tres meses, asumiendo el cuarenta por ciento de los pagos que deben realizar las empresas a sus empleados. Con similar propósito, se autorizó la cancelación, con cargo a recursos del Estado, de la mitad del valor de la prima de servicios de los empleados regulares. En esta misma dirección, Finagro estableció el Proyecto Colombia Agro-Produce que tantas críticas ha desatado a nivel nacional, a tal punto que se ha comparado, en su utilización, con el malogrado Agro Ingreso Seguro.

\section{ALGUNAS GRANDES DEFRAUDACIONES A TRAVÉS DE SUBSIDIOS Y SUBVENCIONES}

A la par que ciudadanos honestos han utilizado en debida forma los subsidios y subvenciones del Estado y con su actitud han contribuido al desarrollo económico de algunos sectores de la economía, otros han obtenido estos apoyos en forma irregular o les han dado una aplicación diferente a aquella para la cual fueron autorizados, generando así un grave perjuicio al orden económico social. A continuación reseñamos algunos de ellos:

Dietrich Oehler relata dos defraudaciones que sorprendieron a la Comunidad Económica Europea. Para mayor claridad, transcribimos lo expuesto por el doctrinante:

En los años 60, una de las mayores empresas carniceras de Europa había suministrado cerdos de matanza a una sociedad suiza perteneciente a un amigo del primer empresario, con el que, además, tenía otra empresa en común en Basilea. Por esta exportación a Suiza, un país no perteneciente a la CEE, recibió el empresario en cuestión una subvención a la exportación de aproximadamente 300.000 DM de los servicios de depósito que a la sazón regulaban tales operaciones, subvención que tenía por finalidad compensar la diferencia existente entre el precio en la CEE, más elevado, y el precio inferior del mercado internacional, de modo que la mercancía procedente de la CEE resultara competitiva en el mercado mundial. Por otra parte, Suiza no permitía por aquel entonces la importación de cerdos, por motivos sanitarios, hecho que era conocido por nuestro exportador. Los cerdos se remitieron aquel mismo día a Italia. Para la exportación directa a Italia, en su calidad de país miembro de la CEE, no se pagaba ninguna compensación en semejante cuantía. Como consecuencia de la entrega a través de Suiza, la industria carnicera alemana pudo embolsarse, 
así pues, cuantiosas subvenciones sin que se hubiera producido exportación alguna a un país ajeno a la $\mathrm{CEE}^{42}$.

El segundo caso referido se relaciona con el envío de mantequilla desde Hamburgo hacia el norte de África, exportación beneficiada por generosas subvenciones. Empero, la mercancía no se desembarcó en el lugar inicial de destino, sino que se desvío hacia una zona del Este donde el reconocimiento de la Comunidad Económica era menor. Por esta irregular operación, los responsables recibieron una compensación del orden de 28 millones de $\operatorname{marcos}^{43}$.

En Colombia, la obtención fraudulenta de subvenciones a través de exportaciones e importaciones ficticias ha sido recurrente. Por ejemplo, al revisar los anales criminales del país se encuentra que en febrero de 1992 la desaparecida Superintendencia de Control de Cambios impuso multas por $\$ 19.000$ millones contra 232 personas naturales y jurídicas que simulaban exportaciones con el objeto de lavar dólares. También fueron muy sonados los casos del cobro fraudulento de exportaciones de sal con destino al Ecuador que luego terminó vendiéndose en el interior del país o la pretendida exportación mentirosa de 36.364 litros de un químico denominado lavandol y, finalmente, para hablar de eventos más recientes, en el año 2011, el apoderamiento ilícito de cerca de un billón de pesos por parte de funcionarios y exfuncionarios de la Dirección de Impuestos Nacionales que, empleando empresas ficticias, se hicieron a recursos que la DIAN devolvía por concepto de IVA, por las exportaciones de cuero, textiles y chatarra ${ }^{44}$.

En cuanto a importaciones ficticias, también existe un amplio historial en el país. En el gobierno del general Gustavo Rojas Pinilla se detectó una serie de maniobras de algunas personas que se aprovecharon en forma ilícita del mayor valor del dólar callejero, simulando el ingreso al país de bienes de procedencia extranjera. El diario El Tiempo reseñó en los siguientes términos la situación:

Los agentes comerciales del régimen depuesto obtuvieron varios millones de pesos por la "importación de ganado" mediante un juego muy hábil, que les permitía contar con dólares oficiales a discreción. Esos personajes, bien conocidos de la opinión, compraban determinada cantidad de ganado en Córdoba o Bolívar, lo embarcaban y realizaban el cabotaje por Panamá y luego

42 Dietrich Oehler. "El fraude en las subvenciones", en AA. vV. Los delitos socioeconómicos, Marino Barbero Santos (ed.), Madrid, Universidad Complutense de Madrid, 1985, pp. 303-304.

43 Ibídem, p. 304.

44 Una completa reseña de casos de exportaciones e importaciones ficticias se puede encontrar en: Hernando A. Hernández Quintero. "Los delitos de exportación o importación ficticia y aplicación fraudulenta de crédito oficialmente regulado frente al punible de fraude a subvenciones", en Cuadernos de Derecho Penal Económico, n. . 7, Ibagué, Universidad de Ibagué, 2013, pp. 90-96. 
entraba en el país como de procedencia panameña o costarricense. El negocio consistía en obtener dólares oficiales que vendían luego en bolsa negra por el doble o el triple de su valor, según el mercado interno de esa moneda, y para la compra del ganado utilizaban pesos colombianos ${ }^{45}$.

En el pasado reciente, sobre este odioso comportamiento puede recordarse la detección de licencias falsas de importación que amparaban el ingreso al país de ropa usada proveniente del exterior con destino a los desplazados, la cual debía ser distribuida por algunas fundaciones. En los contenedores se encontraron mercancías de contrabando avaluadas en 1005 millones de $\operatorname{pesos}^{46}$.

Otra gran defraudación se presentó en Colombia con la utilización indebida del subsidio del programa de Protección del Ingreso Cafetero (PIC). En efecto, se autorizó que el productor, luego de vender el grano, presentara la factura correspondiente a las cooperativas y comités cafeteros, los cuales autorizaban el giro del subsidio. Sin embargo, en 2013 se detectó el cobro irregular de este beneficio, por lo que la Federación Nacional de Cafeteros formuló denuncia ante la Fiscalía General de la Nación por 25.200 operaciones sospechosas de fraude ${ }^{47}$.

Por otra parte, la Fiscalía colombiana investigó la asignación de apoyos económicos destinados a cofinanciar proyectos de infraestructura de riego y drenaje entregados en los años 2007 y 2008, al amparo del proyecto Agro Ingreso Seguro, y estableció que muchos de ellos fueron obtenidos en forma ilícita a través del fraccionamiento ficticio de predios, maniobra que generó beneficios a grupos empresariales o familiares por cerca de $\$ 25.087 .499 .66^{[48]}$.

\section{LA RESPUESTA PENAL AL FRAUDE AL CRÉDITO Y A LAS SUBVENCIONES}

Ante el fracaso del derecho administrativo sancionador para enfrentar el fraude en el crédito y en las subvenciones, y ante la convicción respecto a la importancia de mantener estos estímulos, los países han tipificado en sus estatutos penales normas con las que se pretende estabilizar la protección al sistema económico y sancionar a quienes, en forma indebida, obtienen estos recursos o los utilizan en actividades diferentes a aquellas para las cuales fueron otorgados. A continuación reseñamos algunas de esas disposiciones.

45 El Tiempo. "Otra actividad del pasado régimen", sección "Hace 50 años", 29 de mayo de 2007, p. 2.

46 El Tiempo, 28 de julio de 2003,pp. 1 y 5.

47 Semana. "Avivatos", n. ${ }^{\circ} 1617,29$ de abril de 2013, p. 66.

48 Corte Suprema de Justicia, sentencia rad. 37462. 


\subsection{Legislaciones extranjeras}

En Alemania, en la primera Ley contra la Delincuencia Económica, que entró en vigencia el 1. ${ }^{\circ}$ de septiembre de 1976, se introdujo la figura penal del fraude a subvenciones para sancionar a quienes obtienen ventajas económicas del Estado por exportaciones que no se han realizado o por la obtención de créditos sin tener derecho a ellos ${ }^{49}$. Actualmente, en el Estatuto expedido el 15 de mayo de 1871, con la sexta reforma al Derecho Penal, del 26 de enero de 1998, en el parágrafo 264, se consagra el ilícito en estudio como "fraude en las subvenciones" 50.

El Código Penal italiano ubica el fraude a subvenciones como una forma de estafa agravada. En el artículo 640 bis, titulado "Estafa agravada por la obtención de erogaciones públicas", sanciona con pena de reclusión de uno a seis años la obtención ilícita de cualquier ayuda concedida por el Estado y la extiende a los apoyos otorgados por la Comunidad Económica Europea ${ }^{51}$.

En España, el comportamiento estudiado se incluyó desde el Proyecto de Ley Orgánica del Código Penal de 1980 como un delito contra la hacienda pública. En la Ley de 29 de abril de 1985 se ubicó como artículo 350 del Estatuto Penal. Más tarde, en la Ley Orgánica 10 de 1995, conocida como Nuevo Código Penal, la figura se trasladó al artículo 308; luego fue modificada por la Ley Orgánica 7 de 27 de diciembre de 2012 y ubicada como un delito contra la Hacienda Pública y la Seguridad Social, en el título XIII, conocido como "Delitos contra el patrimonio y contra el orden socioeconómico".

\subsection{La legislación colombiana}

En 1980, luego de cuarenta y cuatro años de vigencia del Estatuto punitivo de 1936, con clara orientación positivista, en Colombia se adoptó un código penal bajo la influencia de la corriente técnico-jurídica. En esta codificación, siguiendo de cerca algunos criterios del Proyecto de Código Penal que entonces se discutía en España, se crea el título VII, con el propósito de proteger el bien jurídico conocido como "orden económico social", cuyo alcance fue explicado por los comisionados en los siguientes términos:

49 Ricardo Ángel Basílico, Hernando A. Hernández Quintero y Matías Carlos Froment. Delitos contra el orden económico y financiero, Buenos Aires, Bogotá, Astrea, Universidad del Rosario, 2018, p. 7.

50 Hernando A. Hernández Quintero. Los delitos económicos en la actividad financiera, 8. a ed., Bogotá, Grupo Editorial Ibáñez, 2018,p. 377.

51 Hernando A. Hernández Quintero. "El nuevo delito de fraude a subvenciones”, en Revista de Derecho Penal y Criminología, vol. XXXIV, n. ${ }^{\circ}$ 96, enero-junio, Bogotá, Universidad Externado de Colombia, 2013, p. 37. 
Los llamados, pues, delitos económicos y más concretamente, contra el “orden económico", tutelan la organización que el Estado intervencionista de hoy establece, para que la sociedad alcance los fines que le son propios. Por eso marca el acento en la expresión "orden". De manera que todo lo que tienda a perturbar o romper dicho sistema u "orden", debe sufrir la sanción correspondiente. En la protección de ese orden, como es lógico, resalta el "interés público", por sobre el individual o particular de los banqueros, comerciantes, industriales, agricultores, ganaderos, etc., los que también resultan tutelados de manera refleja o mediata ${ }^{52}$.

En el estatuto comentado, dada la reiteración de conductas que procuraban obtener ilícitamente beneficios del Estado, se crearon dos tipos penales: la "exportación ficticia" (art. 240) y la "aplicación fraudulenta de crédito oficialmente regulado" (art. 241). Como puede verse, se procuró sancionar actuaciones puntuales y no el fenómeno amplio del fraude a subvenciones. En el Código Penal de 2000 (Ley 599), estos tipos penales fueron ubicados como artículos 310 y 311 en el título x, que mantuvo la denominación de "Delitos contra el orden económico social", con algunas modificaciones que con insistencia sugirió la doctrina, entre ellas, que debía incluirse el comportamiento de la importación ficticia al lado de la exportación ficticia y eliminarse la expresión "finalmente", que se había agregado, en forma maliciosa, al artículo 241 por el Decreto 172 de 1980 y que tornaba en imposible sancionar a quienes utilizaban mal el crédito, pues, finalmente, cuando se acercaba el tiempo máximo que se les había concedido, destinaban el crédito para el fin original.

Por otra parte, cuando se presentó la investigación por la obtención indebida de subvenciones del programa Agro Ingreso Seguro, la administración de justicia no encontró que estos comportamientos se ajustaran a los tipos que tradicionalmente se habían creado para cobijar esta clase de conductas y, en consecuencia, terminó condenando a los particulares por los delitos de peculado por apropiación y falsedad en documentos públicos y privados, y al ex ministro de Estado Andrés Felipe Arias Leyva por los delitos de contrato sin cumplimiento de requisitos legales y peculado por apropiación ${ }^{53-54}$. La situación comentada impulsó al legislador colombiano a adicionar al Código Penal vigente el punible de fraude a subvenciones (art. 403A), que se incluyó por vía del nuevo Estatuto Anticorrupción (Ley 1474 de 2011).

Por consiguiente, en la actualidad la exportación o importación ficticia, la aplicación fraudulenta de crédito oficialmente regulado y el fraude a subvenciones, a pesar de

52 Luis Carlos Giraldo Marín. Actas del nuevo Código Penal colombiano, vol. II, Bogotá, Pequeño Foro, 1981, p. 371.

53 Sentencia de la Corte Suprema de Justicia, rad. 37.462.

54 La Corte Constitucional, al resolver una tutela, decidió que esta decisión judicial puede ser sometida a recurso de apelación para dar plena aplicación al principio de la doble instancia. 
representar todas un fraude a subvenciones, se sancionan en tres tipos penales distintos (arts. 310, 311 y 403A del Código Penal), ubicados en títulos diferentes; los dos primeros, como punibles que afectan el orden económico social, y el último, como un ilícito contra la administración pública. A continuación reseñamos estos tres tipos penales, con el fin de evidenciar su especial relación:

Artículo 310. Exportación o importación ficticia. El que con el fin de obtener un provecho ilícito de origen oficial simule exportación o importación, total o parcialmente, incurrirá en prisión de dos (2) a ocho (8) años [hoy 32 meses a 144 meses] y multa de cincuenta (50) a quinientos (500) [hoy 66,66 a 750] salarios mínimos legales mensuales vigentes.

Artículo 311. Aplicación fraudulenta de crédito oficialmente regulado. El que con destino a actividades fomentadas por el Estado obtenga crédito oficialmente regulado y no le dé la aplicación a que está destinado, incurrirá en prisión de uno (1) a tres (3) años [hoy 16 meses a 54 meses].

Artículo 403A. Fraude a subvenciones. El que obtenga una subvención, ayuda o subsidio proveniente de recursos públicos mediante engaño sobre las condiciones requeridas para su concesión o callando total o parcialmente la verdad, incurrirá en prisión de cinco (5) a nueve (9) años, multa de doscientos (200) a mil (1000) salarios mínimos legales mensuales vigentes e inhabilidad para el ejercicio de derechos y funciones públicas de seis (6) a doce (12) años.

Las mismas penas se impondrán al que no invierta los recursos obtenidos a través de una subvención, subsidio o ayuda de una entidad pública a la finalidad a la cual están destinados.

Como puede verse claramente, el delito de exportación o importación ficticia del artículo 310 guarda una estrecha relación con el punible de fraude a subvenciones, pues cuando un ciudadano o una empresa "simule" una de estas operaciones con el propósito de obtener indebidamente un provecho del Estado, es igual a que obtenga la subvención mediante "engaño", ingrediente normativo que utiliza el artículo 403A. Podría decirse que la única diferencia está en que, en razón de los verbos rectores utilizados en los dispositivos penales, el primer comportamiento es de peligro (simular) y el segundo de resultado (obtener). En tal evento, estaríamos frente a un concurso aparente de tipos penales que, a nuestro juicio, se desataría utilizando el criterio de la especialización.

Ahora bien: en cuanto a la aplicación fraudulenta de crédito oficialmente regulado, reseñado en el artículo 311, también puede encontrarse un posible conflicto de normas con el artículo 403A, segundo inciso, pues ambos se refieren a que las personas que han obtenido un crédito, para el primer caso, o una subvención, subsidio o ayuda, para el segundo, y no lo aplican al propósito para el cual estaba destinado, incurren en las 
correspondientes consecuencias punitivas. Señalamos lo anterior porque si bien el crédito se diferencia de la subvención en que este debe cancelarse mientras aquella no, en ciertas ocasiones el crédito se efectúa con una subvención; por ejemplo, con amplios plazos o tasas de interés más bajas que las del mercado, asumiendo el Estado el costo de dicha operación. Tal es el caso de los créditos que son redescontados por entidades como Finagro o Bancoldex.

Bien podría decirse, además, que existe una diferencia entre la aplicación fraudulenta del crédito y el fraude a subvenciones puesto que el crédito puede ser concedido por una entidad pública o privada, mientras que la subvención solo se concreta cuando los recursos son públicos. No obstante, tal diferencia tampoco es sustancial, pues en algunos eventos el crédito es concedido por entidades estatales como el Banco Agrario o, a pesar de ser otorgado el crédito por conducto de un banco privado, los recursos provienen de programas del Estado, como los relacionados con el sector agropecuario o industrial y por eso son redescontados por bancos de segundo piso.

Las anteriores consideraciones nos llevan a reiterar el planteamiento que hemos efectuado en varios escenarios, en el sentido de que las tres figuras analizadas en los párrafos precedentes - la exportación o importación ficticia, la aplicación fraudulenta de crédito oficialmente regulado y el fraude a subvenciones- deben ser unificadas en un solo tipo penal que se denomine, justamente, fraude a subvenciones, como aparece en el artículo 308 del Código Penal español, y se ubique como un delito contra el orden económico social, pues este es el que resulta más afectado cuando se obtienen recursos del Estado en forma fraudulenta o se destinan a otros fines diferentes a aquellos para los cuales fueron aprobados, frustrando así los planes del Gobierno de impulsar un determinado sector de la economía y privando, injustamente, de estas subvenciones a quienes si los aprovecharían en favor del desarrollo del país.

Asimismo es necesario, tal como lo establece también el Código Penal español, que estas conductas se sancionen por vía penal solo cuando la defraudación supere una cantidad de salarios mínimos legales, con lo que se evita que pequeñas defraudaciones vengan a congestionar aún más el sistema judicial. En tales casos, la sanción debe estar a cargo del derecho administrativo sancionador; por ejemplo, obligando a la devolución de la subvención y castigando a la persona con no tener en el futuro derecho a estos incentivos del Estado.

\section{EL FRAUDE A SUBVENCIONES EN ÉPOCA DEL COVID-19}

Como es conocido, desde finales de 2019 el país, al igual que el resto del mundo, vive una situación de incertidumbre debida a la pandemia de la enfermedad por coronavirus, conocida como covid-19, que ha obligado a los gobiernos a adoptar medidas de urgencia para tratar de evitar su veloz contagio. Entre dichas medidas está el confinamiento de los ciudadanos en sus hogares, que ha afectado la producción y generado la inactividad o reducción de algunas empresas y, por consiguiente, la 
pérdida de muchos empleos, además de la reducción en el consumo, lo cual permite presagiar una crisis semejante o superior a la de la década de 1930, cuando se presentó el crack de la bolsa en Nueva York.

Para enfrentar las dificultades comentadas y con el objeto de evitar el derrumbe del aparato productivo del país, el Gobierno, como ya se comentó, decidió aprobar algunas líneas de crédito a través de los bancos, muchas de ellas con el aval del Fondo de Garantías, así como otorgar a los empresarios el subsidio a la nómina y a la prima legal de servicios.

Pues bien, puede suceder que las empresas, por intermedio de sus representantes legales o personas naturales con más de tres empleados, obtengan del Estado los créditos o subsidios analizados, utilizando para ello información engañosa o callando total o parcialmente la verdad, caso en el cual incurrirían en el punible de fraude a subvenciones del artículo 403A, inciso primero. También es posible que en tales casos este comportamiento concurse con el delito de falsedad, postura doctrinal aceptada en forma prácticamente unánime ${ }^{55}$.

Así mismo, si la subvención se ha obtenido legítimamente pero no se aplica a los fines para los cuales estaba destinada, por ejemplo, no se cancelan los salarios o la prima correspondiente a los empleados, se actualiza el delito de fraude a subvenciones, en los términos consagrados en el inciso segundo del artículo 403A.

Por último, si se trata de un crédito con subsidio, al que se le desvía su prístino destino, la conducta se podrá investigar y juzgar como un ilícito de aplicación fraudulenta de crédito oficialmente regulado, conforme a la descripción del artículo 311 de la Cartilla de Penas.

\section{CONCLUSIONES}

Tras el abandono de los postulados de la escuela liberal clásica, emerge la intervención del Estado en la economía, corriente que considera que se debe impulsar algunos sectores productivos a través de la concesión de créditos subsidiados o entregando determinadas subvenciones.

En muchas ocasiones los créditos y subvenciones se obtienen de manera fraudulenta o se desvían hacia actividades diferentes a aquellas para las cuales fueron otorgados, con lo cual se retrasa o se impide el desarrollo de los sectores económicos que el Estado está interesado en impulsar.

55 Ignacio Berdugo Gómez de la Torre y Juan Carlos Ferré Olivé. Todo sobre el fraude tributario, Barcelona, Praxis, 1994, p. 145. 
Ante la poca efectividad del derecho administrativo sancionador para prevenir y castigar estos comportamientos desviados, el legislador ha decidido crear tipos penales que sancionen ejemplarmente a quienes traicionan los propósitos del Estado interventor.

En Colombia, ante la creciente utilización indebida de los créditos y las subvenciones, el legislador incluyó desde el Código Penal de 1980 los delitos de exportación ficticia y la aplicación fraudulenta de crédito oficialmente regulado, comportamientos que fueron ampliados en el Estatuto Penal del año 2000, en el cual se considera también delictivo el comportamiento de la importación ficticia.

Con el fin de disminuir el impacto de la globalización de la economía y los efectos de la suscripción del tratado de libre comercio con Estados Unidos, el Congreso de Colombia aprobó el programa de Agro Ingreso Seguro, propuesto por el gobierno de turno. Desafortunadamente este bien intencionado proyecto fue mal utilizado por algunos grupos empresariales que fragmentaron en forma ilícita sus predios para obtener una mayor subvención. Comoquiera que este odioso proceder no encontró acomodo en los tipos penales existentes, el legislador colombiano creó el nuevo delito de fraude a subvenciones, contenido hoy en el artículo 403A, del Código Penal.

La existencia en la legislación colombiana de tres tipos penales que buscan un propósito similar-sancionar el mal uso de los créditos subsidiados y las subvenciones-nos impulsa a proponer que se unifiquen en uno que se denomine fraude a subvenciones y se ubique en el título décimo del Código Penal que protege el bien jurídico denominado orden económico social.

La obtención fraudulenta de los subsidios creados por el Estado colombiano para paliar los efectos de la covid-19 o la desviación de estos hacia fines diferentes a aquellos para los que fueron otorgados actualizan el tipo penal de fraude a subvenciones tipificado en el artículo 403A del Código Penal. Si la desviación de los recursos se produce sobre créditos subsidiados, el ilícito sería el de aplicación fraudulenta de crédito oficialmente regulado, según las voces del artículo 311 del Estatuto Penal.

\section{REFERENCIAS}

AA. VV. Crisis financiera colombiana en los años noventa, origen, resolución y lecciones institucionales, Bogotá, Universidad Externado de Colombia, 2009.

Andrade Castro, Jason Alexander. “Aproximación a los nuevos tipos penales para combatir la corrupción”, en AA. VV. XXXIV Jornadas de Derecho Penal, Bogotá, Universidad Externado de Colombia, 2012, pp. 9-71.

Angarita Barón, Ciro. "La libertad económica en la jurisprudencia de la Corte Constitucional: aproximación fugaz”, en AA. VV. Constitución económica colombiana, Bogotá, El Navegante, 1997, pp. 165-182. 
Ángel Basílico, Ricardo; Hernández Quintero, Hernando y Froment, Matías Carlos. Delitos contra el orden económico y financiero, Buenos Aires, Bogotá, Astrea, Universidad del Rosario, 2018.

Berdugo Gómez de la Torre, Ignacio y Ferré Olivé, Juan Carlos. Todo sobre el fraude tributario, Barcelona, Praxis, 1994.

De Pombo, Joaquín. "Dinámica del sector agrícola colombiano", en AA. vv. La economía colombiana, Bogotá, Banco de la República, 1995, pp. 247-273.

Fernández Farreres, Germán. La subvención: concepto y régimen jurídico, Madrid, Instituto de Estudios Fiscales, 1983.

Giraldo Marín, Luis Carlos. Actas del nuevo Código Penal Colombiano, vol. II, Bogotá, Pequeño Foro, 1981.

Gómez, Hernando J. "Antecedentes y evolución del crédito de fomento en Colombia y su relación con el Banco Central”, en AA. vV. El Banco de la República: antecedentes, evolución y estructura, Bogotá, Banco de la República, 1990, pp. 677-708.

Gómez Rivero, María del Carmen. "Fraude a subvenciones", en AA. VV. Diccionario de derecho penal económico, Javier Boix Reig (dir.) y Paz Lloria García (coord.). Madrid, Iustel, 2008, pp. 497-512.

Guinard Hernández, David. "La 'regulación económica' como instrumento de dirección estatal en la economía", Revista digital de Derecho Administrativo, n. ${ }^{\circ} 18$, julio-diciembre, Bogotá, Universidad Externado de Colombia, 2017, pp. 177-224.

Hernández Quintero, Hernando A. "El nuevo delito de fraude a subvenciones", Revista de Derecho Penal y Criminología, vol. XxxIv, n. . 96, enero-junio, Bogotá, Universidad Externado de Colombia, 2013, pp. 31-55.

Hernández Quintero, Hernando A. "Los delitos de exportación o importación ficticia y aplicación fraudulenta de crédito oficialmente regulado frente al punible de fraude a subvenciones", en AA. VV. Cuadernos de derecho penal económico, n. ${ }^{\circ} 7$, Hernando A. Hernández Q. (ed. acad.), Universidad de Ibagué, 2013, pp. 87-133.

Hernández Quintero, Hernando A. Los delitos económicos en la actividad financiera, 8. . ed., Bogotá, Grupo editorial Ibáñez, 2018.

Ibáñez Nájar, Jorge Enrique. "La reforma de 1951”, en AA. vv. El Banco de la República: antecedentes, evolución y estructura, Bogotá, Banco de la República, 1990, pp. 443-462. 
Laurent, Muriel. Contrabando en Colombia en el siglo XIX, prácticas y discursos de resistencia y reproducción, Bogotá, Universidad de los Andes, 2008.

Ocampo, José Antonio; Arias, Paola y Torres, Juan David. "La banca nacional de desarrollo en Colombia”, Ensayos de Política Económica, n. ${ }^{\circ} 88$, Bogotá, Banco de la República, 2018, pp. 1-36.

Oehler, Dietrich. "El fraude en las subvenciones", en AA. Vv. Los delitos socioeconómicos, Marino Barbero Santos (ed.), Madrid, 1985, pp. 299-315.

Ortega, Francisco J. "Evolución y políticas de administración de las líneas de crédito externo para el sector privado", en AA. vV. Tres banqueros centrales, Adolfo Meisel Roca y María Teresa Ramírez (eds.), Bogotá, Banco de la República, 2017, pp. 135-152.

Palacios Mejía, Hugo. La economía en el derecho constitucional colombiano, t. I, Bogotá, Biblioteca ANIF, 1975.

Palacios Mejía, Hugo. "Notas acerca de la facultad de regular la economía en la Constitución de 1991", Revista de Derecho Público, n. ${ }^{\circ}$ 1, Bogotá, Universidad de los Andes, 1992, pp. 39-55.

Pérez Escobar, Jacobo. Derecho constitucional colombiano, Bogotá, Horizontes, 1974.

Perry Rubio, Guillermo. “Estado y sector privado en la Constitución de 1991”, en Constitución económica colombiana, Bogotá, El Navegante, 1997, pp. 123-139.

Sáchica, Luis Carlos. Nuevo constitucionalismo colombiano, 10. a ed., Bogotá, Temis, 1992.

Sánchez López, Virginia. El delito de fraude a subvenciones en el nuevo Código Penal, Madrid, Constitución y Leyes, 1997.

Smith, Adam. La riqueza de las naciones, Madrid, Alianza, 2008. 